\title{
Behavior of Decomposed Ammonia Borane at High Pressure
}

\author{
Yongzhou Sun ${ }^{1}$, Jiuhua Chen ${ }^{1,2, *}$, Vadym Drozd ${ }^{1}$, Shah Najiba ${ }^{1}$
}

${ }^{1}$ Center for the Study of Matter at Extreme Condition (CeSMEC), Department of Mechanical and Materials Engineering, Florida International University (FIU), Miami, FL33199

${ }^{2}$ Center for High Pressure Science and Technology Advanced Research, Changchun 130015, China

*Corresponding Author. Email: chenj@ fiu.edu; tel: +1(305)348-3030; fax: +1(305)348-3070

Abstract: High pressure behavior of ammonia borane after thermal decomposition was studied by Raman spectroscopy at high pressure up to $10 \mathrm{GPa}$ using diamond anvil cell (DAC). The ammonia borane was decomposed at around 140 degree Celsius under the pressure at $\sim 0.7 \mathrm{GPa}$. Raman spectra show the hydrogen was desorbed within 1 hour. The hydrogen was sealed in DAC well and cooled down near to room temperature. Applying higher pressure up to 10 GPa indicates interactions between the products and loss of dihydrogen bonding. No rehydrogenation was detected in the pressure range investigated.

Keywords: Inorganic compounds; Raman spectroscopy; Phase transitions; Thermodynamic properties; High pressure

\section{Introduction}

Ammonia borane [1] [2]is considered to be a very promising on-board hydrogen storage material because of its high hydrogen density (19.6 wt \% of hydrogen) and mild hydrogen releasing conditions $[1,3]$ :

$$
\begin{array}{ll}
n \mathrm{NH}_{3} \mathrm{BH}_{3}(s) \rightarrow\left[\mathrm{NH}_{2} \mathrm{BH}_{2}\right] n(s)+n \mathrm{H}_{2}(g) & \text { at } 100^{\circ} \mathrm{C}(\mathrm{l}) \\
{\left[\mathrm{NH}_{2} \mathrm{BH}_{2}\right] n(s) \rightarrow[\mathrm{NHBH}] n(s)+n \mathrm{H}_{2}(g)} & \text { at } 160^{\circ} \mathrm{C}(2) \\
{[\mathrm{NHBH}] n(s) \rightarrow n \mathrm{BN}(s)+n \mathrm{H}_{2}(\mathrm{~g})} & \text { at } 500^{\circ} \mathrm{C}(3)
\end{array}
$$

However, there are several barriers to overcome to take this hydrogen storage material into application. One of the barriers is the low hydrogen desorption rate. Recently, hydrolysis [4-7], nano confinement [8-16], acid initiation [17], ionic liquids [6], and other methods have been reported to decrease the decomposition temperature and increase the hydrogen desorption rates.

Another barrier is low or non-rechargeability of ammonia borane after dehydrogenation. Pressure is an important tool for hydrogen storage [18-20]. Although it has been reported that ammonia borane can hardly be rehydrogenated directly after decomposition by high pressure[21], Lin's group successfully used high pressure put more extra hydrogen into ammonia borane at room temperature[19]. On the other hand, interactions between BNH compounds and hydrogen under high pressure [22-24] were detected by Raman studies, which impose possibilities to recharge hydrogen back into decomposed ammonia borane. To study the mechanism of decomposition and interaction between NBH compounds and hydrogen, some fundamental research should be conducted first. While a lot of work has already been reported, many issues such as the detailed decomposition mechanism, the rehydrogenation property, and the dihydrogen bonding effect still remain unclear. So study the behavior between the NBH compounds and hydrogen at high pressure is still meaningful. Previous studies of ammonia borane has been focused on infrared (IR) and Raman spectroscopy [19, 20, 25-28], $\mathrm{X}$-Ray diffraction[29-31], nuclear magnetic resonance (NMR)[14, 32], theoretical computation[30, 33-35], neutron scattering[36-39], and anelastic spectroscopy[40], etc. Pressure influence on the crystal structure evolution of ammonia borane has been recently reviewed [41]. Here we report our study on the high pressure behavior between decomposed ammonia borane, which are first-step decomposition product poly-amidoborane $(\mathrm{PAB})$ and second step decomposition product poly- 
imidoborane (PIB), interacted with hydrogen in DAC using in situ Raman spectra.

\section{Experiment}

The ammonia borane, $\mathrm{NH}_{3} \mathrm{BH}_{3}$, sample was purchased from Sigma-Aldrich Co. and was used without any additional purification. The sample was loaded in the Mao-Bell type diamond anvil cell (DAC) with a culet size of $400 \mu \mathrm{m}$. Sample chamber was a hole of 150-200 $\mu \mathrm{m}$ in diameter and 60$80 \mu \mathrm{m}$ in thickness in the stainless steel or beryllium-copper alloy foil. No pressure transmitting medium was used [21]. Ruby chips were loaded in the sample chamber as well for pressure calibration. Ruby fluorescence method with temperature correction $[42,43]$ was used to determine the pressure inside the DAC.

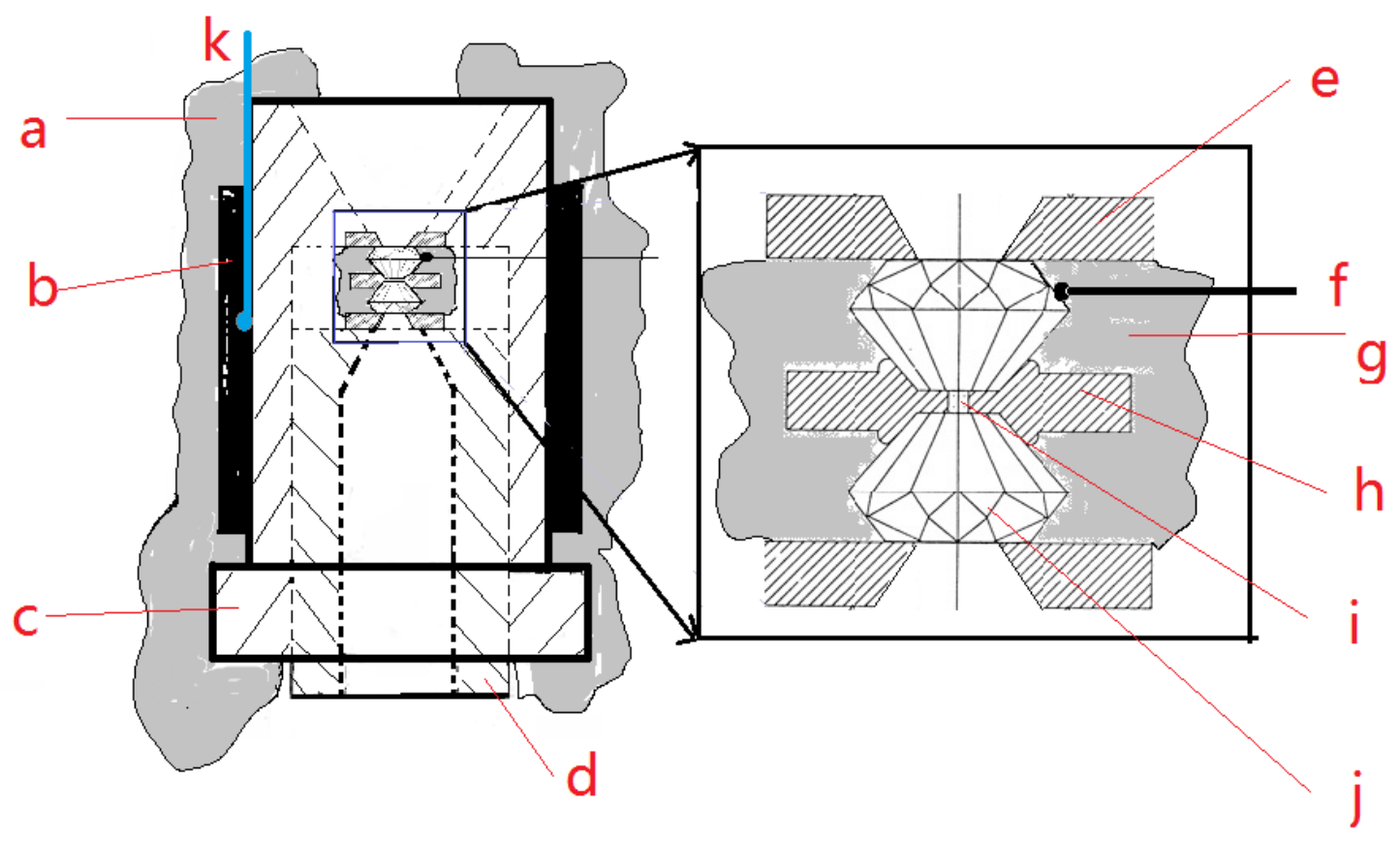

Fig. 1 The experimental system used in the high pressure and high temperature experiments. a: asbestos; b: heater; c: DAC cylinder; d: DAC piston; e: Diamond anvil seats; f: first thermocouple; g: asbestos; h: gasket; i: sample; j: diamond anvil; k: second thermocouple.

As shown in fig. 1, high temperature in DAC was achieved using a resistive nichrome toroidaltype heater surrounding the outside of DAC. The temperature was measured using two K-type thermocouples: the first one is positioned near the sample chamber in contact with the diamond anvil, and the second one was positioned near the heater for temperature control. The sample temperature is reflected by the first thermocouple, which is $20-40{ }^{\circ} \mathrm{C}$ lower than the second one due to the temperature gradient between the heater and diamond. The temperature was controlled using a Delta DTB4824 thermal controller. The cell was isolated from surrounding using several layers of thermal insulation (asbestos) and kept at the desired temperatures within $\pm 2^{\circ} \mathrm{C}$. Raman spectra were recorded in the back-scattering configuration. An argon ion laser $\left(\mathrm{Ar}^{+}\right)$operated at $\sim 108 \mathrm{~mW}$ of power was used to excite the sample. The scattering signals were collected with an exposure time of 2 min using a high throughput holographic imaging spectrograph with volume transmission grating, holographic notch filter and thermoelectrically cooled CCD detector (Andor).

After the closure of the DAC, the ammonia borane sample was heated to $\sim 140{ }^{\circ} \mathrm{C}$ to make sure the first equivalent of hydrogen molecule was released but sealed in the gasket by initial pressure at $\sim 0.7 \mathrm{GPa}$. Then the sample was cooled down to room temperature and the pressure was increased step 
by step with an interval of $\sim 0.7 \mathrm{GPa}$. At each compression step, pressure was held for a few minutes before any measurement. Ruby fluorescence from ruby chips at different location in the sample chamber indicates that the pressure in the cell is nearly hydrostatic although we did not use any pressure medium. The Raman spectra of the sample at room temperature and ambient pressure agree well with previous study.

\section{Result and discussions}

Similar to the previous work[20,28], the Raman spectra we collected were analyzed separately in several regions: $\mathrm{NH}$ stretching (NH str.) region $\left(3150 \mathrm{~cm}^{-1}-3350 \mathrm{~cm}^{-1}\right)$, BH stretching (BH str.) region $\left(2250 \mathrm{~cm}^{-1}-2550 \mathrm{~cm}^{-1}\right)$, BN stretching (BN str.) region $\left(700 \mathrm{~cm}^{-1}-1000 \mathrm{~cm}^{-1}\right)$, BH bending (BH ben.) region $\left(1150 \mathrm{~cm}^{-1}-1300 \mathrm{~cm}^{-1}\right)$, NH bending (NH ben.) region $\left(1450 \mathrm{~cm}^{-1}-1700 \mathrm{~cm}^{-1}\right)$.

As shown in fig. 2, ammonia borane was decomposed after heated to $\sim 140{ }^{\circ} \mathrm{C}$ for 1 hour. The second spectrum from top shows the Raman shifts of decomposed products cooled to room temperature, which contains first step decomposition product poly-amidoborane (PAB), second step decomposition product poly-imidoborane (PIB) and molecular hydrogen. It has been declared that the byproducts (such as diborane, borazine and ammonia) could be decomposed from ammonia borane at ambient pressure, but we did not see obivious peaks of these by products from our Raman study at $\sim 0.7 \mathrm{GPa}$. At $\sim 140{ }^{\circ} \mathrm{C}, 1$ equivalent of hydrogen molecule was estimated to be decomposed from ammonia borane and we did see the strong hydrogen peaks ( $S$ and Q modes) at $\sim 580$ and $\sim 4300 \mathrm{~cm}^{-1}$, however, while the growing of $\mathrm{N}-\mathrm{H}$ stretching mode $v_{\mathrm{s}}\left(\mathrm{NH}_{2}\right)$ from $\mathrm{PAB}$, we also found the $\mathrm{N}-\mathrm{H}$ stretching mode $v_{s}(\mathrm{NH})$ mode from PIB $[23,24]$ indicating the occurrence of the second step decomposition. After the second spectrum, the spectra from top to bottom show the Raman shifts of the products dependent as a function of pressure. No rehydrogenation (reappearance of characteristic Raman peak) of ammonia borane was observed. But a new peak near the Q(1) mode of hydrogen was observed at high pressure, in addition to the intensity decrease of the hydrogen peaks. This new peak did not disappear even after the pressure was decreased near to ambient pressure when the cell was opened. The location of this new peak is consistent with previous reports[23, 24]. As we estimated, the peak was due to interaction between hydrogen and decomposed ammonia borane in their interface, which indicates even though the products of PAB and PIB cannot be rehydrogenated by chemistry reaction, they can still absorb hydrogen physically. The physic-sorption effect can be quenched to very low pressure that near ambient condition.

Another important finding that should be mentioned here is the dihydrogen bonding effect, which has been discussed in many Raman studies under high pressure [20, 27, 33, 44, 45]. As a result of B$\mathrm{H} \cdots \mathrm{H}-\mathrm{N}$ dihydrogen bond [26, 27], the frequency of B-H stretching shifts positively and the frequency of $\mathrm{N}-\mathrm{H}$ stretching shifts negatively when pressure increases. As a comparison, the high pressure Raman spectra study of neat ammonia borane was also conducted at room temperature up to $\sim 10 \mathrm{GPa}$, as shown in fig. 3, where the $\mathrm{N}-\mathrm{H}$ stretching region and $\mathrm{N}-\mathrm{H}$ bending region show negative pressure dependence due to dihydrogen bonding effect. This study was highly consistent with previous reports $[18,20]$ in terms of Raman peaks position of different modes, and phase transitions were also observed at similar pressures. Contrarily, the peaks in the N-H stretching region $\left(3150 \mathrm{~cm}^{-1}\right.$ $\left.3350 \mathrm{~cm}^{-1}\right)$ and $\mathrm{NH}$ bending region $\left(1450 \mathrm{~cm}^{-1}-1700 \mathrm{~cm}^{-1}\right)$ of PAB and PIB show positive pressure dependence (fig. 4) within a hydrogen circumstance, other than negative dependence (fig. 3) of neat ammonia borane or no dependence as previous reported[23, 24]. The previous reports which declared no dependence may due to lack of high pressure data since they only compressed the sample up to 3 GPa. This phenomenon shows the di-hydrogen effect was lost after the decomposition of ammonia borane. 

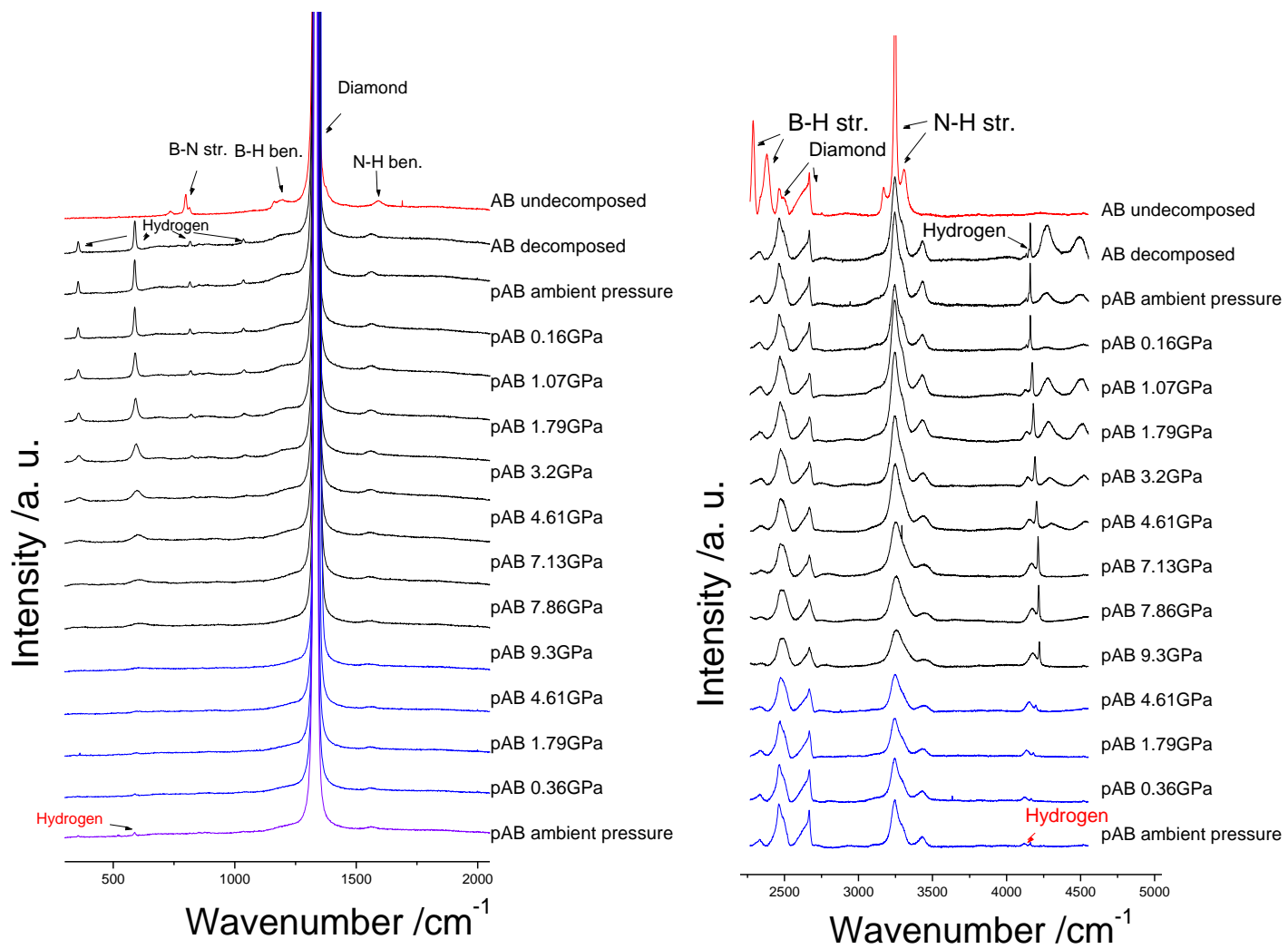

Fig. 2 Raman spectra of $\mathrm{H}_{2}$ and Polyiminoborane (PIB) at $20{ }^{\circ} \mathrm{C}$. From top to bottom: the neat ammonia borane and decomposed ammonia borane at different pressures. All the spectra are measured at room temperature in a Mao-Bell type diamond anvil cell. Different modes from ammonia borane $(\mathrm{AB}), \mathrm{H}_{2}, \mathrm{pAB}$ and diamonds are marked in the first spectrum. $\mathrm{pAB}$ : poly-amidoborane; $\mathrm{AB}$ : ammonia borane; Ben.: bending; Str.: stretching.
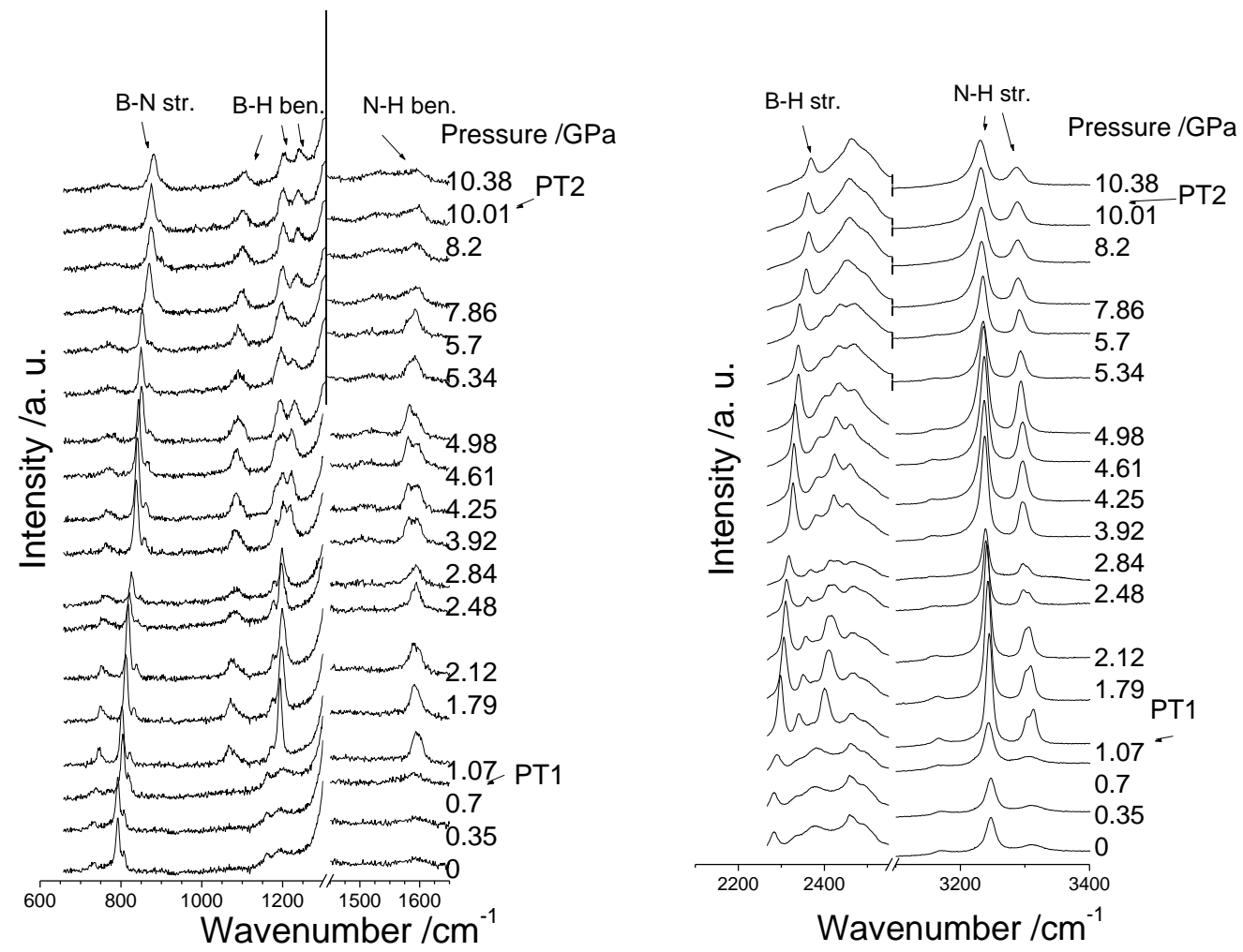

Fig. 3 Raman spectra of ammonia borane as pressure increases from bottom to top. PT1: phase transition 1; PT2: phase transition 2. 
For further comparison, we compressed the decomposed PAB and PIB after we open the DAC to release the decomposed molecular hydrogen, as shown in fig. 4. Here, without the hydrogen circumstance, the $\mathrm{N}-\mathrm{H}$ stretching mode $v_{\mathrm{s}}\left(\mathrm{NH}_{2}\right)$ from $\mathrm{PAB}$ still shows positive pressure dependence but the slop is much lower, while the N-H stretching mode $v_{s}(\mathrm{NH})$ mode from PIB shows no big difference, which indicates hydrogen indeed interact with $\mathrm{PAB}$ and it will affect the $\mathrm{N}-\mathrm{H}$ bonding of PAB while the similar effect between hydrogen and PIB was not detected. Fig. 5 shows the detailed pressure dependence of the $\mathrm{N}-\mathrm{H}$ stretching mode from PAB, PIB and ammonia borane. These phenomenon could also be evidences of that the PIB is thermodynamically more difficult to be rehydrogenated than that of PAB.

If we compare the two spectra of neat ammonia borane (fig. 3) and decomposed PAB and PIB(fig. 2 and fig. 4), another interesting phenomena can be detected: while the peaks in the NH stretching region $\left(3150 \mathrm{~cm}^{-1}-3350 \mathrm{~cm}^{-1}\right)$ and $\mathrm{NH}$ bending region $\left(1450 \mathrm{~cm}^{-1}-1700 \mathrm{~cm}^{-1}\right)$ shows only slightly shift with pressure, the peaks in $\mathrm{BH}$ stretching region $\left(2250 \mathrm{~cm}^{-1}-2550\right.$ $\left.\mathrm{cm}^{-1}\right)$ and $\mathrm{BH}$ bending region $\left(1150 \mathrm{~cm}^{-1}-1300\right.$ $\mathrm{cm}^{-1}$ ) are almost disappeared completely. By these phenomena, we can conclude that the B-H bond is much weaker than N-H bonds and the hydrogen that comes from ammonia borane to form hydrogen molecule are mostly from the broken of B-H bonds. Or there may be another possibility that an intermediate phase, the ionic dimer diammoniate of diborane (DADB) [2, 46], is favored to let $\mathrm{B}-\mathrm{H}$ bonds other than $\mathrm{N}-\mathrm{H}$ bonds to be broken first. The Raman spectra showed similar decomposition pathway now that we applied initial pressure at $\sim 0.7 \mathrm{GPa}$, compared to other experiments at near ambient pressures or higher pressures [21, 47, 48]. This uneven decomposition between B-H bonds and $\mathrm{N}-\mathrm{H}$ bonds is strongly related to the dative bonds in ammonia borane structure due to the difference of the electro-negativity of borane and nitrogen atoms, which is also the reason that the dihydrogen bonding is formed. The broken of B-H bonding can also explain the disappearance of dihydrogen bonding from this view.

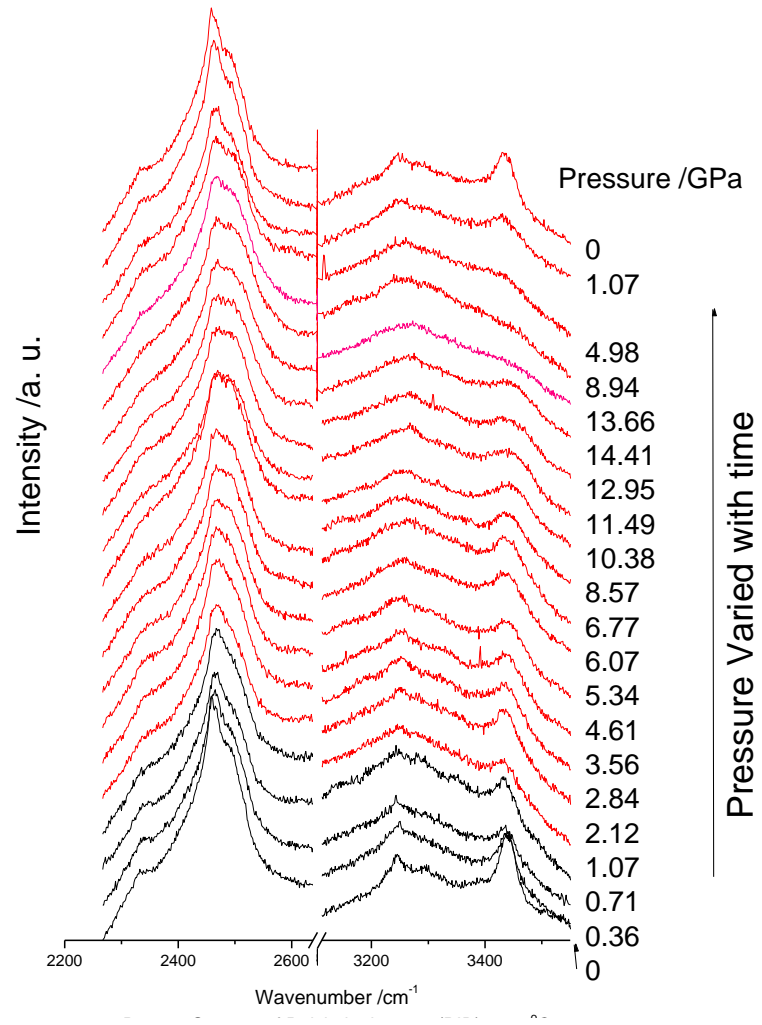

Fig. 4 Raman spectra of Ploy-amidoborane and Poly-imidoborane (without $\mathrm{H}_{2}$ ) during compression (from bottom up) and decompression.

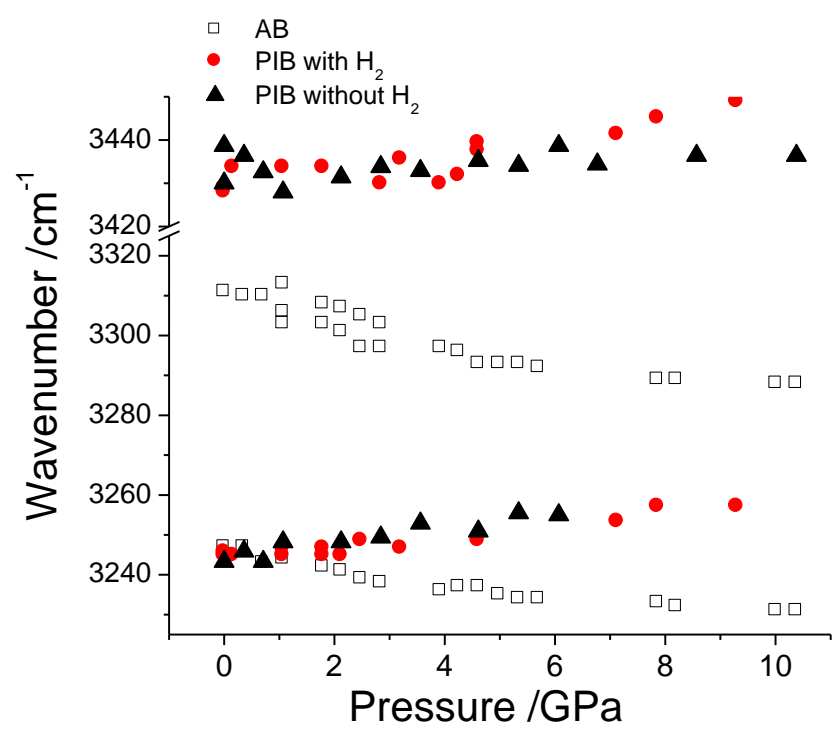

Fig. 5 Pressure dependence of the $\mathrm{N}-\mathrm{H}$ stretching mode from PAB, PIB and ammonia borane. 


\section{Conclusion}

Ammonia borane sample was decomposed at $0.7 \mathrm{GPa}$ and 140 degree Celsius and the decomposed molecular hydrogen, PAB and PIB were detected. Compressing on the decomposed products up to $10 \mathrm{GPa}$ at ambient temperature did not revise the decomposition reaction. We found the PAB and PIB can storage extra hydrogen by physic-sorption. The di-hydrogen bonding effect on pressure dependence of B-H Raman modes was not found whether with or without hydrogen circumstance after decomposition of ammonia borane. Ammonia borane is a promising on-board hydrogen materials and still need to be further studied.

Acknowledgement: This work was supported by the Department of Energy DOE under Award No. DE-FG02-07ER46461, EFree, an Energy Frontier Research Center funded by DOE-BES under Award Number DESC000105, and the Florida International University Dissertation Year Fellowship.

\section{Reference}

[1] M.G. Hu, R.A. Geanangel, W.W. Wendlandt, The thermal decomposition of ammonia borane, Thermochimica Acta, 23 (1978) 249-255.

[2] S.G. Shore, R.W. Parry, The Crystalline Compound Ammonia-Borane, $1 \mathrm{H}_{3} \mathrm{NBH}_{3}$, Journal of the American Chemical Society, 77 (1955) 6084-6085.

[3] G. Wolf, J. Baumann, F. Baitalow, F.P. Hoffmann, Calorimetric process monitoring of thermal decomposition of B-N-H compounds, Thermochimica Acta, 343 (2000) 19-25.

[4] Z. Xiong, C.K. Yong, G. Wu, P. Chen, W. Shaw, A. Karkamkar, T. Autrey, M.O. Jones, S.R. Johnson, P.P. Edwards, W.I.F. David, High-capacity hydrogen storage in lithium and sodium amidoboranes, Nat Mater, 7 (2008) 138-141.

[5] M. Chandra, Q. Xu, Dissociation and hydrolysis of ammonia-borane with solid acids and carbon dioxide: An efficient hydrogen generation system, Journal of Power Sources, 159 (2006) 855-860.

[6] M.E. Bluhm, M.G. Bradley, R. Butterick, U. Kusari, L.G. Sneddon, Amineborane-Based Chemical Hydrogen Storage: Enhanced Ammonia Borane Dehydrogenation in Ionic Liquids, Journal of the American Chemical Society, 128 (2006) 7748 7749.

[7] M.C. Denney, V. Pons, T.J. Hebden, D.M. Heinekey, K.I. Goldberg, Efficient Catalysis of Ammonia Borane Dehydrogenation, Journal of the American Chemical Society, 128 (2006) 12048-12049.

[8] A. Gutowska, L. Li, Y. Shin, C.M. Wang, X.S. Li, J.C. Linehan, R.S. Smith, B.D. Kay, B. Schmid, W. Shaw, M. Gutowski, T. Autrey, Nanoscaffold Mediates Hydrogen Release and the Reactivity of Ammonia Borane, Angewandte Chemie International Edition, 44 (2005) 3578-3582.

[9] T.K. Nielsen, M. Polanski, D. Zasada, P. Javadian, F. Besenbacher, J. Bystrzycki, J. Skibsted, T.R. Jensen, Improved Hydrogen Storage Kinetics of Nanoconfined NaAlH4 Catalyzed with TiCl3 Nanoparticles, ACS Nano, (2011) null-null.

[10] S. Gadipelli, J. Ford, W. Zhou, H. Wu, T.J. Udovic, T. Yildirim, Nanoconfinement and Catalytic Dehydrogenation of Ammonia Borane by Magnesium-Metal-Organic-Framework-74, Chemistry - A European Journal, (2011) 10.1002/chem.201100090.

[11] M. Fetz, R. Gerber, O. Blacque, C.M. Frech, Hydrolysis of Ammonia Borane Catalyzed by Aminophosphine-Stabilized Precursors of Rhodium Nanoparticles: Ligand Effects and Solvent-Controlled Product Formation, Chemistry - A European Journal, (2011) 10.1002/chem.201003543. 
[12] J. Zhao, J. Shi, X. Zhang, F. Cheng, J. Liang, Z. Tao, J. Chen, A Soft Hydrogen Storage Material: Poly(Methyl Acrylate)-Confined Ammonia Borane with Controllable Dehydrogenation, Advanced Materials, 22 (2010) 394-397.

[13] Z. Li, G. Zhu, G. Lu, S. Qiu, X. Yao, Ammonia Borane Confined by a Metal-Organic Framework for Chemical Hydrogen Storage: Enhancing Kinetics and Eliminating Ammonia, Journal of the American Chemical Society, 132 (2010) $1490-1491$.

[14] L.-Q. Wang, A. Karkamkar, T. Autrey, G.J. Exarhos, Hyperpolarized 129Xe NMR Investigation of Ammonia Borane in Mesoporous Silica, The Journal of Physical Chemistry C, 113 (2009) 6485-6490.

[15] H. Kim, A. Karkamkar, T. Autrey, P. Chupas, T. Proffen, Determination of Structure and Phase Transition of Light Element Nanocomposites in Mesoporous Silica: Case study of NH3BH3 in MCM-41, Journal of the American Chemical Society, 131 (2009) 13749-13755.

[16] S. Sepehri, A. Feaver, W.J. Shaw, C.J. Howard, Q. Zhang, T. Autrey, Cao, Spectroscopic Studies of Dehydrogenation of Ammonia Borane in Carbon Cryogel, The Journal of Physical Chemistry B, 111 (2007) 14285-14289.

[17] F.H. Stephens, R.T. Baker, M.H. Matus, D.J. Grant, D.A. Dixon, Acid Initiation of Ammonia-Borane Dehydrogenation for Hydrogen Storage, Angewandte Chemie International Edition, 46 (2007) 746-749.

[18] S. Xie, Y. Song, Z. Liu, In situ high-pressure study of ammonia borane by Raman and IR spectroscopy, Canadian Journal of Chemistry, 87 (2009) 1235-1247.

[19] Y. Lin, W.L. Mao, H.-k. Mao, Storage of molecular hydrogen in an ammonia borane compound at high pressure, Proceedings of the National Academy of Sciences, 106 (2009) 8113-8116.

[20] Y. Lin, W.L. Mao, V. Drozd, J. Chen, L.L. Daemen, Raman spectroscopy study of ammonia borane at high pressure, THE JOURNAL OF CHEMICAL PHYSICS, 129 (2008) 234509.

[21] J. Nylén, T. Sato, E. Soignard, J.L. Yarger, E. Stoyanov, U. Hussermann, Thermal decomposition of ammonia borane at high pressures, The Journal of chemical physics, 131 (2009) 104506-104507.

[22] M.S. Raja S. Chellappa, Viktor V. Struzhkin, Thomas Autrey, andRussell J. Hemley, Pressure-induced complexation of NH3BH3-H2, THE JOURNAL OF CHEMICAL PHYSICS, 131 (2009).

[23] W.L.M. Shibing Wang, and Tom Autrey, Bonding in boranes and their interaction with molecular hydrogen at extreme conditions, THE JOURNAL OF CHEMICAL PHYSICS, 131 (2009).

[24] T.A. Raja S. Chellappa, Maddury Somayazulu, Viktor V. Struzhkin, and Russell J. Hemley, High-Pressure Hydrogen Interactions with Polyaminoborane and Polyiminoborane, ChemPhysChem, 11 (2010) 93-96.

[25] N.J. Hess, M.E. Bowden, V.M. Parvanov, C. Mundy, S.M. Kathmann, G.K. Schenter, T. Autrey, Spectroscopic studies of the phase transition in ammonia borane: Raman spectroscopy of single crystal $\mathrm{NH}_{3} \mathrm{BH}_{3}$ as a function of temperature from 88 to $330 \mathrm{~K}$, THE JOURNAL OF CHEMICAL PHYSICS, 128 (2008) 034508-034511.

[26] S. Trudel, D.F.R. Gilson, High-Pressure Raman Spectroscopic Study of the Ammonia-Borane Complex. Evidence for the Dihydrogen Bond, Inorganic Chemistry, 42 (2003) 2814-2816.

[27] R. Custelcean, Z.A. Dreger, Dihydrogen bonding under high pressure: A Raman study of BH3NH3 molecular crystal, Journal of Physical Chemistry B, 107 (2003) 9231-9235.

[28] Y. Sun, J. Chen, V. Drozd, A. Durigin, S. Najiba, X. Liu, Phase boundary of pressure-induced I4mm to Cmc2(1) transition in ammonia borane at elevated temperature determined using Raman spectroscopy, International Journal of Hydrogen Energy, 39 (2014) 8293-8302.

[29] J. Chen, H. Couvy, H. Liu, V. Drozd, L.L. Daemen, Y. Zhao, C.-C. Kao, In situ X-ray study of ammonia borane at high 
pressures, International Journal of Hydrogen Energy, 35 (2010) 11064-11070.

[30] Y. Filinchuk, A.H. Nevidomskyy, D. Chernyshov, V. Dmitriev, High-pressure phase and transition phenomena in ammonia borane NH3BH3 from x-ray diffraction, Landau theory, and ab initio calculations, Physical Review B, 79 (2009) 214111-214111.

[31] M.E. Bowden, G.J. Gainsford, W.T. Robinson, Room-temperature structure of ammonia borane, Australian Journal of Chemistry, 60 (2007) 149-153.

[32] O. Gunaydin-Sen, R. Achey, N.S. Dalal, A. Stowe, T. Autrey, High Resolution 15N NMR of the 225 K Phase Transition of Ammonia Borane (NH3BH3): Mixed Order-Disorder and Displacive Behavior, The Journal of Physical Chemistry B, 111 (2007) 677-681.

[33] L. Wang, K. Bao, X. Meng, X. Wang, T. Jiang, T. Cui, B. Liu, G. Zou, Structural and dynamical properties of solid ammonia borane under high pressure, THE JOURNAL OF CHEMICAL PHYSICS, 134 (2011) 024517-024518.

[34] Y. Lin, H. Ma, C.W. Matthews, B. Kolb, S. Sinogeikin, T. Thonhauser, W.L. Mao, Experimental and Theoretical Studies on a High Pressure Monoclinic Phase of Ammonia Borane, The Journal of Physical Chemistry C, 116 (2012) 2172-2178.

[35] M. Ramzan, F. Silvearv, A. Blomqvist, R.H. Scheicher, S. Lebègue, R. Ahuja, Structural and energetic analysis of the hydrogen storage materials $\mathrm{LiNH}_{-}\{2\} \mathrm{BH}_{-}\{3\}$ and NaNH_$\{2\} \mathrm{BH}_{-}\{3\}$ from ab initio calculations, Physical Review B, 79 (2009) 132102.

[36] N.J. Hess, G.K. Schenter, M.R. Hartman, L.L. Daemen, T. Proffen, S.M. Kathmann, C.J. Mundy, M. Hartl, D.J. Heldebrant, A.C. Stowe, T. Autrey, Neutron Powder Diffraction and Molecular Simulation Study of the Structural Evolution of Ammonia Borane from 15 to 340 K, The Journal of Physical Chemistry A, 113 (2009) 5723-5735.

[37] N.J. Hess, M.R. Hartman, C.M. Brown, E. Mamontov, A. Karkamkar, D.J. Heldebrant, L.L. Daemen, T. Autrey, Quasielastic neutron scattering of -NH3 and -BH3 rotational dynamics in orthorhombic ammonia borane, Chemical Physics Letters, 459 (2008) 85-88.

[38] C.M. Brown, T.L. Jacques, N.J. Hess, L.L. Daemen, E. Mamontov, J.C. Linehan, A.C. Stowe, T. Autrey, Dynamics of ammonia borane using neutron scattering, Physica B: Condensed Matter, 385-386 (2006) 266-268.

[39] W.T. Klooster, T.F. Koetzle, P.E.M. Siegbahn, T.B. Richardson, R.H. Crabtree, Study of the N-H $\cdots$ H-B Dihydrogen Bond Including the Crystal Structure of BH3NH3 by Neutron Diffraction, Journal of the American Chemical Society, 121 (1999) 6337-6343.

[40] A. Paolone, O. Palumbo, P. Rispoli, R. Cantelli, T. Autrey, Hydrogen Dynamics and Characterization of the Tetragonalto-Orthorhombic Phase Transformation in Ammonia Borane, The Journal of Physical Chemistry C, 113 (2009) 5872-5878.

[41] J. Chen, V. Drozd, Y. Sun, S. Najiba, Ammonia borane at high pressures, Chin. Sci. Bull., DOI 10.1007/s11434-0140619-5 (2014).

[42] REKHI, S., DUBROVINSKY, L. S., SAXENA, S. K., Temperature-induced ruby fluorescence shifts up to a pressure of $15 \mathrm{GPa}$ in an externally heated diamond anvil cell, Pion, London, ROYAUME-UNI, 1999.

[43] H.K. Mao, J. Xu, P.M. Bell, Calibration of the Ruby Pressure Gauge to 800 kbar Under Quasi-Hydrostatic Conditions, J. Geophys. Res., 91 (1986) 4673-4676.

[44] S. Najiba, J. Chen, V. Drozd, A. Durygin, Y. Sun, Tetragonal to orthorhombic phase transition of ammonia borane at low temperature and high pressure, Journal of Applied Physics, 111 (2012) 112618-112615.

[45] S. Najiba, J. Chen, V. Drozd, A. Durygin, Y. Sun, Ammonia borane at low temperature down to 90 K and high pressure up to $15 \mathrm{GPa}$, International Journal of Hydrogen Energy, 38 (2013) 4628-4635. 
[46] D.J. Heldebrant, A. Karkamkar, N.J. Hess, M. Bowden, S. Rassat, F. Zheng, K. Rappe, T. Autrey, The effects of chemical additives on the induction phase in solid-state thermal decomposition of ammonia borane, Chemistry of Materials, 20 (2008) 5332-5336.

[47] F. Baitalow, G. Wolf, J.P.E. Grolier, F. Dan, S.L. Randzio, Thermal decomposition of ammonia-borane under pressures up to 600 bar, Thermochimica Acta, 445 (2006) 121-125.

[48] F. Baitalow, J. Baumann, G. Wolf, K. Jaenicke-Rößler, G. Leitner, Thermal decomposition of B-N-H compounds investigated by using combined thermoanalytical methods, Thermochimica Acta, 391 (2002) 159-168. 